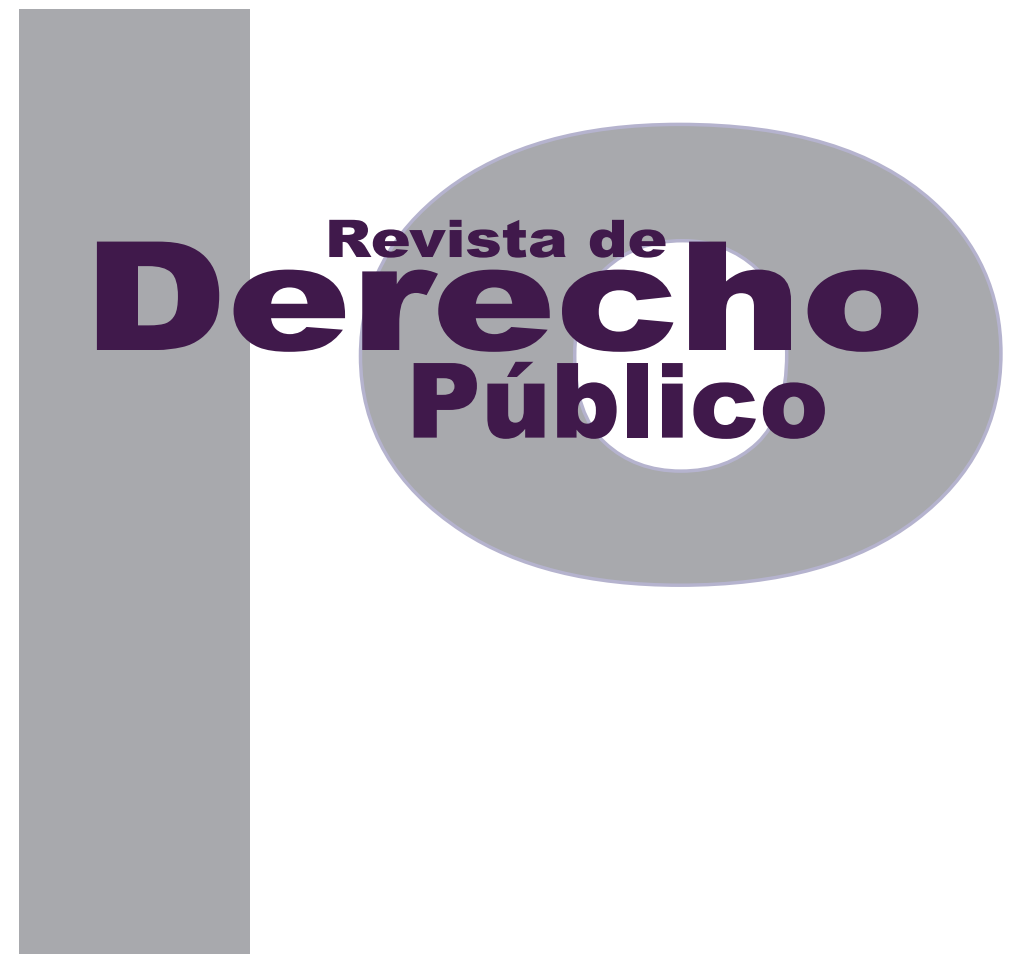

COLOMBIA, ENTRE LA SEGURIDAD DEMOCRÁTICA Y LA PAZ. EL PROCESO ELECTORAL DE 2014: ¿PRIMER PASO HACIA UNA TRANSFORMACIÓN CONSTITUCIONAL?

\author{
RENATA AMAYA \\ Artículo de reflexión \\ DOI: http://dx.doi.org/10.15425/redepub.33.2014.22 \\ Universidad de los Andes \\ Facultad de Derecho \\ Revista de Derecho Público N. ${ }^{\circ} 33$ \\ Julio - Diciembre de 2014. ISSN 1909-7778
}




\title{
Colombia, entre la seguridad democrática y la paz. El proceso electoral de 2014: ¿primer paso hacia una transformación constitucional?
}

\section{Resumen}

A continuación se presenta una reflexión sobre las posibilidades y riesgos que se derivan para Colombia del proceso electoral que culminó el pasado 15 de junio de 2014, en términos de imaginar un escenario que dé pie a un nuevo proceso constituyente y que se enmarque en la propuesta del nuevo constitucionalismo. Se parte de asumir la existencia de una profunda radicalización de dos posiciones políticas similares ideológicamente, pero con hondas diferencias frente al proceso para la consecución de la paz. A partir de esta afirmación, la pregunta específica consiste en establecer si dadas las circunstancias políticas actuales, es posible señalar que se está gestando el terreno para activar el poder constituyente, de forma tal, que propicie un proceso de transformación constitucional. Adicionalmente, se quiere problematizar si necesariamente este proceso derivaría en una Constitución que afiance la carta de derechos, las estrategias de igualdad material y la paz como un requerimiento social esencial para la convivencia pacífica de los colombianos o si, por el contrario, podría conducir a una Constitución legítima pero que refleje un retroceso en materia de derechos, por un fracaso del proceso y una radicalización conservadora. Se concluye que, independientemente de lo que ocurra, se están sentando las bases de un proceso constituyente, ya sea para legitimar el acuerdo de paz o para buscar rebelarse frente a aquel repitiendo, con ello, la historia circular en la que ha vivido el país durante tantas décadas. La reflexión está basada en un análisis documental de prensa y textos teóricos.

Palabras clave: proceso constituyente, proceso constitucional, poder constituido, nuevo constitucionalismo, constitucionalismo, proceso de paz, proceso electoral, legitimidad democrática, fortalecimiento democrático, polarización política, transformación constitucional.

\section{Colombia between democratic security and peace. The 2014 presidential elections: First step towards a constitutional transformation?}

\begin{abstract}
This text presents a reflection on the possibilities and risks arising for Colombia from the electoral process, which culminated last June 15, 2014, in terms of imagining a scenario which gives standing to a new constituent process and that is framed in the proposal of the new constitutionalism. The starting point is that in Colombia there has been a profound radicalization of two political positions, very similar ideologically but with deep differences in terms of the achievement of peace. From this statement, the specific question is to establish if given the current political circumstances, it is possible to point out that the ground for an activation of the constituent power that is conducive to a process of constitutional transformation is brewing. Additionally, the author wants to discuss whether this process would necessarily lead to a Constitution that would deepen the Charter of rights, material equality strategies and peace as a social requirement essential for the peaceful coexistence of the Colombians or if on the contrary, it could result in a legitimate Constitution, but that reflects a decline in terms of rights, by a failure of the process and a conservative radicalization. Regardless to what happens, the bases of a constituent process are making either to legitimize the peace agreement or to search for a rebellion directed to perpetuate the circular story in which the country has lived for so many decades. This reflection is based on a documentary analysis, from two types of sources of information: press and theoretical texts.

Keywords: constituent process, constitutional process, constituted power, new constitutionalism, constitutionalism, peace process, electoral process, democratic legitimacy, democratic strengthening, political polarization constitutional transformation.

\section{Colômbia, entre a segurança democrática e a paz. O processo eleitoral de 2014: primeiro passo para uma transformação constitucional?}

\section{Resumo}

A seguir é apresentada uma reflexão sobre as possibilidades e riscos que se derivam para a Colômbia do processo eleitoral que culminou no dia 15 de junho de 2014, em termos de imaginar um cenário que dê pé a um novo processo constituinte e que se emoldure na proposta do novo constitucionalismo. Se parte de assumir a existência de uma profunda radicalização de duas posições políticas similares ideologicamente, mas com profundas diferenças frente ao processo para a consecução da paz. A partir desta afirmação, a pregunta específica consiste em estabelecer se dadas as circunstancias políticas atuais, é possível assinalar que se está gestando o terreno para ativar o poder constituinte que propicie um processo de transformação constitucional. Adicionalmente, se problematiza se necessariamente este processo derivaria em uma Constituição que afiance a carta de direitos, as estratégias de igualdade material e a paz como um requerimento social essencial para a convivência pacífica dos colombianos ou se, pelo contrário, poderia derivar em uma Constituição legítima mas que reflita um retrocesso em matéria de direitos, por um fracasso do processo e uma radicalização conservadora. Se conclui que independentemente do que ocorra se estão sentando as bases de um processo constituinte, já seja para legitimar o acordo de paz ou para buscar a rebelião frente à história circular na que ha vivido o país durante tantas décadas. A reflexão está baseada em uma análise documental de imprensa e textos teóricos.

Palavras-chave: processo constituinte, processo constitucional, poder constituído, novo constitucionalismo, constitucionalismo, processo de paz, processo eleitoral, legitimidade democrática, fortalecimento democrático, polarização política, transformação constitucional. 


\title{
Colombia, entre la seguridad democrática y la paz. El proceso electoral de 2014: ¿primer paso hacia una transformación constitucional?*
}

\author{
Renata Amaya**
}

"el triunfo de las democracias no ha pasado de ser una derrota de algunos autoritarismos, sin que los modelos sustitutorios cuenten con la mayor de la legitimidad en su instauración y desarrollo, hasta el punto de que en poco tiempo parece haberse pasado de la euforia al escepticismo" (Martínez Dalmau, 2012, p. 11).

\begin{abstract}
SUMARIO
Introducción - I. UN NACIENTE MOVIMIENTO DE OPINIÓN: GÉNESIS DE UN POSTERIOR MOVIMIENTO SOCIAL - II. ELEMENTOS DEL NUEVO CONSTITUCIONALISMO EN EL CASO COLOMBIANO: ¿UNA SEGUNDA CONSTITUYENTE? - A. EI nueVO constitucionalismo: una breve aproximación - B. Presencia de algunos elementos para un proceso constituyente desde el nuevo constitucionalismo en el caso colombiano, a partir del proceso electoral de 2014 - 1. Necesidad o ruptura: paz o guerra, dos caras de la misma moneda - 2. La legitimidad democrática de la Constitución: el poder constituyente - III. BREVES CONCLUSIONES: PROCESO CONSTITUYENTE INCONCLUSO, UN PROCESO EN PERMANENTE CONSTRUCCIÓN, EN PERMANENTE TRANSICIÓN... - Referencias.
\end{abstract}

* Cómo citar este artículo: Amaya, R. (Diciembre, 2014). Colombia, entre la seguridad democrática y la paz. El proceso electoral de 2014: ¿primer paso hacia una transformación constitucional? Revista de Derecho Público, 33. Universidad de los Andes (Colombia).

** Abogada y antropóloga de la Universidad de los Andes. M. A. in Political and Social Sciences (mayor in Liberal Studies) en New School for Social Research. Docente de cátedra de la Facultad de Derecho de la Universidad de los Andes y coordinadora de Investigaciones Dirigidas y del Programa Sócrates de la misma institución. Está realizando el doctorado en Estudios Políticos y Relaciones Internacionales en la Universidad Nacional de Colombia. Correo: ramaya@uniandes.edu.co 


\section{Introducción}

A continuación se presenta una reflexión analítica prospectiva que se derivó de algunos de los planteamientos discutidos en la clase Procesos constituyentes y nuevas constituciones latinoamericanas, dictada por el profesor Rubén Martínez Dalmau, durante el mes de junio de 2014, en el marco del doctorado y la maestría en Derecho de la Universidad Nacional de Colombia. Particularmente se pretende realizar una primera aproximación que, aunque incompleta, presente las posibilidades y riesgos que se derivan para Colombia del proceso electoral que culminó el pasado 15 de junio de 2014, en términos de imaginar un escenario que dé pie a un nuevo proceso constituyente y que se enmarque en el esquema y en los elementos formales y sustanciales del nuevo constitucionalismo.

El cuestionamiento que inquieta a la autora surge de la radicalización de dos posiciones políticas muy similares ideológicamente ${ }^{1}$ pero que presentan profundas diferencias en la concepción de un elemento esencial: la consecución de la paz para un país que lleva más de sesenta años en medio de un conflicto armado inconcluso, deteriorado, y que además de haber dejado miles de víctimas, ha significado la caracterización de Colombia como un país profundamente violento pero con una gran capacidad de adaptación económica frente a la circunstancia

1 Conforme a lo establecido por Rodrigo Uprimny (profesor de la Universidad Nacional de Colombia y columnista del periódico El Espectador): Juan Manuel Santos representa a la derecha republicana y Óscar Iván Zuluaga a la extrema derecha, liderada en Colombia por el expresidente Álvaro Uribe Vélez (7 de junio de 2014). anterior, ${ }^{2}$ situación que en sí misma constituye un problema: convivir con la violencia.

En esta medida, la reelección del presidente candidato Juan Manuel Santos Calderón significa para Colombia la continuación del proceso de diálogo iniciado con las Fuerzas Armadas Revolucionarias de Colombia (FARC), el grupo guerrillero insurgente que más tiempo ha sobrevivido en la historia reciente, y posiblemente con el también grupo guerrillero insurgente Ejército de Liberación Nacional (ELN). Este proceso de diálogo comenzó formalmente en octubre de 2012 , pero sus antecedentes se remontan a finales de 2010 como lo muestra El Tiempo (s. f.) en la cronología que presenta en el espacio Colombia busca la paz. ${ }^{3}$ Frente a dicho proceso se ha presentado (i) un fuerte respaldo por parte de una franja de la sociedad civil que apoya la idea del presidente Santos (santistas) de avanzar en los diálogos de paz de La Habana sin cese de hostilidades por parte de las Farc ni del Estado, dentro de la mayor confidencialidad, y la propuesta de restituir integralmente a las víctimas; ${ }^{4}$ y (ii)

2 Sobre la situación del conflicto armado interno colombiano vale la pena traer a colación el siguiente fragmento del artículo de Ricardo Sanín, The 'Lawful' Political Killing of Bogotá's Mayor: Gustavo Petro, fechado el 7 de marzo de 2014: "Yet this apparent institutional sturdiness conceals a civil war that has been ongoing for more than sixty years. This war has almost bled rural Colombia to death and has made urban areas a bizarre collage of wealth and poverty. It is a tale of two countries: on one side Colombia has now surpassed Argentina as the third biggest economy in Latin America, heavy foreign investment is lured daily to the country, factories rise, banks flourish. On the other side, Colombia has the world's fourth worst GINI index with only Haiti worse off in its hemisphere. It is a country split at its base, Arcadia and dystopia colliding in every corner of life". Disponible en http:// criticallegalthinking.com/2014/03/07/lawful-political-killing-bogotasmayor/

3 Disponible en: http://www.eltiempo.com/Multimedia/especiales/ proceso-de-paz-colombia/

Ver http://www.urnadecristal.gov.co/busqueda/PROCESO $\% 20$ DE\%20PAZ, consultado el 17 de junio de 2014 . 
una gran oposición por parte de los adeptos del expresidente Uribe (uribistas) que consideran que la paz debe responder a un proceso de negociación que garantice por lo menos el cese unilateral por parte del grupo armado ilegal, sin el hermetismo en que se viene dando y sin la supuesta inexistencia del conflicto armado, para tratar a los guerrilleros como terroristas sin incidencia política. ${ }^{5}$

En este contexto, la pregunta específica consiste en establecer si dadas las circunstancias políticas actuales frente a unos diálogos -que en todo caso terminarán o con el establecimiento de un acuerdo cuya legitimidad y validez deberá ser ratificada por el poder constituyente a través de un referendo, o con la finalización de las negociaciones y la consecuente continuidad de la guerra, que seguramente también conllevará un proceso constituyente por la erosión del poderes posible señalar que se está abonando el terreno para la activación del poder constituyente con miras a un proceso de transformación cons-

5 A continuación se presenta una síntesis de la posición del candidato Óscar Iván Zuluaga frente al proceso de paz, en entrevista concedida al periódico El Tiempo, seis días antes de la segunda vuelta electoral ocurrida el 15 de junio de 2014, y que evidencia lo planteado respecto al proceso de paz y la que sería una política fiscal de su gobierno: "Vamos a dar un tiempo prudencial para exigir el cumplimiento de unas condiciones que permitan avanzar en la búsqueda de una paz negociada y, en ese intervalo, no se suspenderían las negociaciones. [El rompimiento de las negociaciones es una] "opción después de que las Farc reflexionen sobre la importancia de que este es un proceso en serio, que tiene que tener límites. Es que las Farc llevan dos años de vacaciones en La Habana, sin ninguna exigencia; están en el mejor de los mundos: siguen reclutando niños (3 mil el año pasado), ponen minas antipersonas, asesinan soldados y policías a sangre fría, extorsionan, secuestran, atentan contra la infraestructura del país. No es posible la búsqueda de una paz negociada así". Ver "Desmontaré la reforma tributaria que se hizo contra la clase media. El candidato Zuluaga sugiere que puntos acordados en La Habana no comprometerían un gobierno suyo". En: http://www.eltiempo.com/ politica/partidos-politicos/scar-ivan-zuluaga-explica-su-posicionactual-frente-al-proceso-de-paz/14089417 titucional que contenga los elementos del nuevo constitucionalismo. ${ }^{6}$ Adicionalmente, se quiere problematizar, o por lo menos dejar abierta la pregunta, sobre si necesariamente este proceso derivaría en una Constitución que afiance la carta de derechos, las estrategias de igualdad material y la paz como un requerimiento social esencial para la convivencia pacífica de los colombianos o, por el contrario, en una Constitución legítima pero con un retroceso en materia de derechos, producto del fracaso del proceso de paz y de la radicalización conservadora.

La hipótesis de la que se parte es la siguiente: el escenario político colombiano actual, ${ }^{7}$ que se ha caracterizado por una fuerte polarización entre dos bandos del mismo espectro político, ha sentado las bases para el inicio de un eventual proceso de cambio constitucional en el que se pondrían en juego dos elementos sustanciales básicos: el control del enemigo a través de la violencia, o la incorporación del enemigo como parte de la sociedad civil, a través del proceso de paz. De una u otra opción puede surgir un eventual proceso constituyente que podría dar

6 Posiblemente con los elementos propios del nuevo constitucionalismo latinoamericano, pero con la probabilidad de presentar otros que muestren, además, cómo en esta corriente teórica se articulan teoría y práctica, como sugieren varios exponentes de ella.

7 Como se ha afirmado desde el inicio del presente texto, el proceso electoral que ha vivido Colombia en el año 2014 se ha caracterizado por una gran polarización entre los seguidores del expresidente Álvaro Uribe Vélez, hoy senador electo con una votación de más de dos millones de votos y con una bancada de 19 congresistas, y los seguidores de presidente Juan Manuel Santos -o tal vez, los opositores de Uribe y seguidores del proceso de paz-. Ver a propósito de la opción que presentaba el candidato presidente Juan Manuel Santos Calderón el artículo: Las urnas no definieron el pulso entre Uribe y Santos. En http://lasillavacia.com/historia/historia-analisiselecciones-46842 Consultado el 17 de junio de 2014. 
lugar a una ruptura profunda encaminada en una de dos direcciones:

1. El afianzamiento de la propuesta conservadora.

2. El afianzamiento de la propuesta progresista que se inició en 1989 con el movimiento de la Séptima papeleta o como también se ha denominado: Todavía podemos salvar a Colombia.

Finalmente, una aclaración metodológica. Las fuentes utilizadas fueron de dos tipos: artículos de prensa y textos teóricos que hablan sobre los procesos constituyentes y el nuevo constitucionalismo. Respecto a la primera, se consultaron los siguiente medios: la revista Semana; los periódicos El Tiempo, El Espectador y El País; y La Silla Vacía, medio interactivo alternativo frente al manejo que tradicionalmente ha dado a la información la prensa escrita, la televisión y la radio en Colombia.

\section{UN NACIENTE MOVIMIENTO DE OPINIÓN: GÉNESIS DE UN POSTERIOR MOVIMIENTO SOCIAL}

Partiendo de la hipótesis planteada, es decir, que en Colombia se está comenzando a montar el escenario para una reforma constitucional desde el ejercicio del poder constituyente, en el marco del nuevo constitucionalismo, es importante señalar previamente que, además, se dan los elementos propios de formación de movimientos sociales, conforme a lo que al respecto afirma Touraine y que retoma Óscar Alejandro
Quintero Ramírez en su texto Sociología e historia del movimiento estudiantil por la Asamblea Constituyente de 1991, es decir, que los movimientos sociales se forman influyendo sobre la opinión pública (2002, p. 143). En efecto, en palabras de Quintero, las reivindicaciones llegan a ser movimiento de opinión cuando se presentan tres elementos: apertura del sistema político e intervención de aliados políticos; naturaleza negociable y no negociable de las reivindicaciones y la intervención de un factor de integración y uno de conflicto para que el movimiento de opinión se convierta en movimiento social (2002, p. 143).

En esta medida, en el proceso electoral colombiano que terminó con la elección como presidente, por segunda vez, de Juan Manuel Santos Calderón, se presentaron los elementos previamente mencionados: en la segunda vuelta el sistema político se vio en la necesidad de abrirse a nuevas vertientes políticas y de incluir a los aliados, como lo prueban las alianzas estratégicas de los dos candidatos: Óscar Iván Zuluaga se alió con el partido Conservador y con Martha Lucía Ramírez quien obtuvo en primera vuelta la tercera votación más alta: casi dos millones de votos (El Tiempo, 26 de mayo de 2014); por su parte, Juan Manuel Santos logró la adhesión de uno de sus supuestos grandes opositores, Gustavo Petro, lo cual resultó por demás paradójico dado que Santos había apoyado, durante los meses previos a la campaña, la destitución de este como alcalde mayor de Bogotá. ${ }^{8}$ Así mis-

$8 \quad \mathrm{Al}$ respecto, vale la pena hacer un breve recuento de lo ocurrido con la decisión mencionada, en la medida en que evidencia los giros jurídicos que se están presentando en Colombia y que constituyen 
mo, contó con la adhesión pública de respetables académicos, senadores y representantes a la Cámara; movimientos sociales representantes de grupos vulnerables como negritudes, prostitutas, víctimas del conflicto interno; diferentes países y organizaciones internacionales; entre otros, ${ }^{9}$ quienes defendieron en los medios de comunicación los motivos para preferir a Santos.

una de las razones para afirmar que se están cimentando las bases de un proceso constituyente desde el nuevo constitucionalismo. La decisión inicial fue tomada por la Sala Disciplinaria de la Procuraduría General de la Nación, el diciembre de 2013; posteriormente el alcalde recusó la decisión del procurador Ordóñez. El 13 de enero de 2014 el procurador negó la recusación y ratificó la destitución e inhabilidad. El 23 de enero de 2014 el Tribunal Administrativo de Cundinamarca falló a favor del alcalde Petro tres acciones de tutela que reclamaban suspender el fallo de destitución de la Procuraduría, como medida cautelar. Unos días después, la Sala Plena del Consejo Superior de la Judicatura negó las acciones de tutela radicadas en contra de la sanción de la Procuraduría y tumbó las medidas cautelares emitidas por el Tribunal. El 18 de marzo el Consejo de Estado dejó en firme la destitución del alcalde Petro y señaló que la Procuraduría General tiene facultades para investigar y sancionar disciplinariamente a un funcionario público elegido por voto popular. Ver: Cronología del proceso de destitución del alcalde Petro, en: http://www.elespectador. com/noticias/bogota/cronologia-del-proceso-de-destitucion-delalcalde-petro-galeria-481701\#. A comienzos de junio de 2014, la Corte Suprema de Justicia (csJ), en el fallo que revocó la tutela con la que la Sala Especializada de Restitución de Tierras del Tribunal Superior de Bogotá restituyó a Petro en la Alcaldía de Bogotá, argumentó que este ha tenido garantías en la justicia, que la solicitud de medidas cautelares por parte de la Corte Interamericana de Derechos Humanos (CIDH) no es obligatoria y que "el Presidente de la República no estaba facultado para obedecer una medida, independientemente de cuál haya sido el órgano que la solicitó, en ese caso, la CIDH. Según el alto tribunal, suspender la destitución que había firmado Santos se aparta de la doctrina sentada por ese mismo organismo (...) [a] consideración de los magistrados, la situación del Alcalde no se ha visto afectada por la desprotección del Estado porque Petro ha tenido y sigue teniendo a su alcance todos los mecanismos para la defensa de sus derechos" (El Tiempo, 8 de junio de 2014). También desestimaron el argumento de desprotección invocado ante las instancias internacionales y que motivó a la $\mathrm{CIDH}$ a considerar el caso como de extrema gravedad y urgencia. No obstante lo anterior, la cs señaló que este fallo no afectaba la permanencia de Petro en la Alcaldía, pues estaban vigentes las medidas cautelares otorgadas por el Consejo de Estado (El Tiempo, 8 de junio de 2014).

9 La revista Semana sintetizó lo ocurrido en la jornada electoral del 15 de junio de la siguiente forma: "Las adhesiones políticas, el respaldo al proceso de paz, el giro al interior de la campaña y el voto anti-uribista le dan el triunfo al candidato presidente" (Semana, 15 de junio de 2014).
Respecto a las reivindicaciones negociables y no negociables, el debate en el país tuvo como eje el proceso de paz $^{10}$ que se viene desarrollando en La Habana entre el Gobierno colombiano y las FARC, y que constituye el factor de integración o de conflicto que caracteriza actualmente al movimiento de opinión, ${ }^{11}$ independiente de la posición de los candidatos -que pretendían ser propuestas, pero se quedaron en lo valorativo-. ${ }^{12}$ En consecuencia, Colombia, al reelegir a Santos Calderón, escogió la continuación del proceso de paz tal y como se está desarrollando en La Habana. Así mismo, el proceso electoral y la elección evidenciaron y ratificaron la polarización del país no solo en materia de votos ${ }^{13}$ sino en términos regionales.

En conclusión, se puede afirmar que están sentadas las bases para la generación de movimientos sociales o de opinión capaces de poner en acción un proceso constituyente. A continua-

10 Ver información oficial en: http://www.urnadecristal.gov.co/busqueda/ PROCESO\%20DE\%20PAZ

11 Al respecto, vale la pena resaltar la visión de Catalina Navarro en su columna Apuesta por la paz (El Espectador, 11 de junio de 2014) en donde pretende ver la paz como un asunto común: "Los colombianos llevamos toda nuestra historia aferrados a la guerra: la más incómoda de las zonas de confort. Por eso es necesario un informe que nos demuestre algo que debería ser intuitivo: estaríamos mejor en tiempos de paz. La guerra les conviene a unos pocos, pero la paz nos conviene a todos". Esto lo afirma la autora en el marco del análisis del informe ¿Qué ganaría Colombia con la paz?, recientemente presentado por el Programa de las Naciones Unidas para el Desarrollo (PNUD), en alianza con el Cerac, en donde se muestran los beneficios económicos que vendrían con el posconflicto.

12 En la etapa previa a las elecciones de segunda vuelta era común escuchar a la gente decir que si se votaba por Santos se votaba a favor de la guerrilla y del Petro-Chavismo, haciendo referencia a un gobierno de izquierda valorado negativamente, y que si se votaba por Zuluaga, se votaba en contra de la paz.

13 En votación el candidato presidente alcanzó el $50.9 \%$, equivalente a 7 816989 votos y el candidato Óscar Iván Zuluaga el 45\%, equivalente a 6904989 votos. 
ción se analiza si es posible afirmar que en el escenario colombiano actual se presentan o no los presupuestos de un proceso constituyente desde la teoría del nuevo constitucionalismo.

\section{ELEMENTOS DEL NUEVO CONSTITUCIONALISMO EN EL CASO COLOMBIANO: ¿UNA SEGUNDA CONSTITUYENTE?}

\section{A. El nuevo constitucionalismo: una breve aproximación}

Para empezar, es importante entender el contexto en el que se habla de un proceso constituyente democrático desde el nuevo constitucionalismo y cómo estos procesos reflejan la estrecha relación entre tres categorías analíticas básicas: "legitimidad del poder público -democracia-, (...) ejercicio de este poder -gobierno- (...) materialización constitucional de los anteriores -constitución, ordenamiento jurídico-" (Viciano y Martínez, 2011, p. 1). Es así como se estaría hablando de un proceso en el que deben interactuar democracia, gobierno y Constitución, pero no limitándose a lo formal sino a transformaciones sustanciales en términos de instituciones jurídicas, políticas, sociales y económicas innovadoras y de derechos. Por su parte, al hablar de nuevo constitucionalismo, estaríamos situándonos en un quinto momento o paradigma que aunque comparte ciertos elementos con el neoconstitucionalismo, también presenta profundas diferencias con dicha postura teórica. En efecto, como señalan Viciano y Martínez: lo más relevante es que el Neoconstitucionalismo es una corriente doctrinal, producto de años de teorización académica mientras que (...) el nuevo constitucionalismo latinoamericano es un fenómeno surgido en el extrarradio de la academia, producto más de las reivindicaciones populares y de los movimientos sociales que de planteamientos teóricos coherentemente armados (2011, p. 7). ${ }^{14}$

Por otro lado, y con fundamento en las diferentes experiencias latinoamericanas en donde el nuevo constitucionalismo ha tomado forma (particularmente los casos de Colombia, Ecuador, Venezuela y Bolivia), vale la pena resaltar que

cada una de las experiencias constituyentes mencionadas se conforma en sí misma como un modelo teórico-práctico propio de proceso constituyente. Pero todas ellas cuentan con un denominador común (...): asumen la necesidad de legitimar ampliamente un proceso constituyente revolucionario $y$, aunque los resultados son en buena medida desiguales, consiguen aprobar constituciones que apun-

14 También vale la pena retomar los elementos característicos del neoconstitucionalismo, para que con la aplicación de los elementos del nuevo constitucionalismo en el caso planteado, se puedan apreciar las diferencias que existen entre los dos procesos: "En definitiva, el Neoconstitucionalismo pretende, sin ruptura, alejarse de los esquemas del positivismo teórico y convertir al Estado de Derecho en el Estado constitucional de Derecho (...). Como teoría del Derecho, el Neoconstitucionalismo - en particular a partir de los principios- aspira a describir los logros de la constitucionalización, entendida como el proceso que ha comportado una modificación de los grandes sistemas jurídicos contemporáneos. Por esta razón, está caracterizado por una constitución invasora, por la positivización de un catálogo de derechos, por la omnipresencia en la constitución de principios y reglas, y por algunas peculiaridades de la interpretación y de la aplicación de las normas constitucionales respecto a la interpretación y aplicación de la ley. Se trata, en definitiva, de recuperar en sentido fuerte la idea de constitución como norma jurídica suprema del Estado y fortalecer su presencia determinadora en el ordenamiento jurídico (Viciano y Martínez, 2011, pp. 6-7). 
tan, en definitiva, hacia el Estado constitucional. Teoría y práctica se unen, por lo tanto, en el nuevo constitucionalismo latinoamericano (Viciano y Martínez, 2011, p. 14).

\section{B. Presencia de algunos elementos para un proceso constituyente desde el nuevo constitucionalismo en el caso colombiano, a partir del proceso electoral de 2014}

\section{Necesidad o ruptura: paz o guerra, dos caras de la misma moneda}

El presente análisis se centra de forma particular en el elemento de necesidad o ruptura para asumir la hipótesis de la que se parte. En efecto, se considera que la necesidad de transformación o la ruptura que termina evidenciando la erosión del poder constituido se ha comenzado a tejer en el contexto colombiano, con una idea profundamente revolucionaria: el proceso de paz, una paz temida por muchos y deseada por otros. Por lo tanto, y sin desconocer los demás elementos formales (originalidad, amplitud, complejidad y rigidez para el cambio) y sustanciales (activación directa del poder constituyente a partir de la incorporación de mecanismos de participación ciudadana vinculantes, una amplia carta de derechos y la integración de diversos sectores tradicionalmente marginados acompañados de movimientos sociales, la aparición de una fuerte normatividad constitucional que permea la totalidad del ordenamiento, constituciones económicas encaminadas a superar las desigualdades) que contemplan Viciano y Martínez (2011, pp. 15-20 y ss.), que de hecho se considera que están presentes aunque suene contradictorio con la idea de nuevo constitucionalismo, por lo menos, de forma nominal- en la actual Constitución Política de nuestro país, por ahora, se afirma la existencia de una naciente pero contundente necesidad.

En este contexto, cuando el pueblo colombiano eligió a Santos y con él la continuación del proceso de negociación con las FARc, también eligió una ardua labor constitucional, que comenzará, de llegar a la concertación, por aceptar lo pactado a través de un referendo, situación que deberá propiciar el presidente electo de los coIombianos en el periodo 2014-2018, en el que, como ya se ha mencionado, debe superar la gran fragmentación. ${ }^{15}$ Esto, a su vez, evidencia la necesidad de repensar algunos presupuestos constitucionales, particularmente aquellos que se relacionan con los puntos de negociación en la mesa de diálogo. Para ilustrar en dónde vamos, Rodrigo Uprimny presenta los temas sobre los que ya se ha logrado cierto acuerdo:

Es un logro inmenso que tengamos ya acuerdos muy razonables en tres temas de la agenda (desarrollo rural, participación política y drogas ilícitas), que han sido factores cruciales en el origen y dinámica de la guerra y sobre los cuales fue imposible avanzar significativamente en el pasado. Hoy la voluntad de la guerrilla

15 En las columnas de opinión de los medios consultados para el presente texto, es claro el siguiente planteamiento: el gobierno actual tiene que concertar con la oposición. Para ilustrar lo anterior, antes de la segunda vuelta Cristina de la Torre, en su columna Mesa de diálogo con el uribismo, expuso lo siguiente: "Si se quiere conjurar todo factor de violencia política y propiciar el advenimiento de un país más justo, será preciso acometer la segunda fase de la tarea: negociar con la ultraderecha, representada en el uribismo duro" (El Espectador, 26 de mayo de 2014). 
por alcanzar la paz parece entonces genuina. Un acuerdo de paz está en el horizonte (24 de mayo de 2014).

Así mismo, existen otros puntos en los que la coyuntura política muestra la necesidad de una eventual reforma constitucional: la abolición de la reelección presidencial, porque esta es producto de la voluntad del expresidente Uribe para perpetuar su mandato, más que resultado del ejercicio del poder constituyente, razón por la que es ampliamente cuestionada; la reforma a la Procuraduría General de la Nación, por considerar que este órgano no tiene suficientes herramientas de control y detenta un poder muy amplio en términos del ejercicio del control disciplinario, como lo demostró con el proceso de destitución y restitución del alcalde Petro; y la reforma de la acción de tutela para controlar su excesiva utilización con el propósito de lograr fines personales, hecho que desgasta el sistema judicial y al mismo mecanismo de protección, como quedó demostrado cuando el alcalde Petro y algunos de sus asesores jurídicos movilizaron al pueblo en lo que se denominó una tutelatón para impedir su destitución.

En últimas, la paz, si se logra, es una apuesta profundamente revolucionaria y emancipadora, condiciones esenciales para hablar de un proceso constituyente desde el nuevo constitucionalismo; sin embargo, no lograrla también abriría el escenario a una posible transformación, que podría ir en dos direcciones: (i) hacia el afianzamiento de los logros emancipadores alcanzados desde la Constitución del 91 o, (ii) hacia un nuevo escenario constitucional poco progresista y alta- mente conservador, incluso de limitación de derechos fundamentales, de llegar a atenderse la propuesta del uribismo y una parte nada despreciable de la ciudadanía que lo sigue, con la política de la seguridad democrática que propone limitar el derecho a la intimidad, a la libertad, entre otros, en función de una supuesta protección de la población frente al terrorismo, representado en Colombia por la guerrilla. Todo esto incidirá en la transformación con gran fuerza, considerando que se trata de la consecución de la paz o de la perpetuación de la guerra, y que cualquiera de las opciones afectará el statu quo y la situación económica de muchos sectores acostumbrados a vivir a expensas de la guerra.

En síntesis, hacen parte de los elementos que evidencian la naciente necesidad o la inicial ruptura del poder constituido, las siguientes circunstancias:

- La coyuntura política y la forma en que se presentó el recién terminado proceso electoral.

- El deterioro de figuras emblemáticas de la Constitución Política como la Procuraduría General de la Nación y la acción de tutela.

- La inseguridad jurídica que se deriva de la destitución-restitución del alcalde Petro. ${ }^{16}$

16 Al respecto, vale la pena señalar dos cosas: 1. Como apuntan Viciano y Martínez: "En el Estado constitucional, la soberanía del Estado solo tiene sentido de forma dependiente - y, por lo tanto, limitada - a la soberanía del pueblo y, por ello, el constitucionalismo democrático exige que la soberanía del Estado solo pueda concebirse en el ámbito de la normatividad" (2011, p. 14). Por ello, la inseguridad jurídica que se ha derivado del caso Petro y que se traduce en quiebre de posiciones entre el gobierno central —aunque oscilando entre los dos bandos - y la Corte Suprema de Justicia, por un lado, y por el otro, el Tribunal Superior de Cundinamarca, el Consejo de Estado y la CIDH, así como en un constante cambio en la decisión de la destitución, dejaron 
- La dramática división política entre uribistas (derecha extrema) y santistas (derecha moderada).

Finalmente, es fundamental contextualizar la necesidad o ruptura en el contexto colombiano de un proceso constituyente en función de la desigualdad que vive el país, la cual se insinuó en la nota 2 que hace referencia al texto The 'Lawful' Political Killing of Bogotá's Mayor: Gustavo Petro, y se evidenció en la división geográfica de la votación (Cárdenas, 16 de junio de 2014).

\section{La legitimidad democrática de la Constitución: el poder constituyente}

Siendo este el eje del nuevo constitucionalismo, es importante entender a qué nos referimos. El poder constituyente habla de la legitimidad del poder político organizado:

Su función legitimadora, apegada a la decisión democrática de la voluntad popular y a su capacidad ilimitada de actuación (soberanía), se ha mostrado presente en la legitimidad del poder político contemporáneo, hasta el punto de que su activación se ha convertido en el elemento distintivo de las democracias constitucionales al legitimar la organización del poder a través de las constituciones (Martínez, 2012, p. 2).

En este contexto, el constitucionalismo democrático y su expresión más reciente, el nuevo constitucionalismo, tienen como presupuesto

en la incertidumbre al poder constituyente, o por lo menos a quienes hacen parte de este en la ciudad de Bogotá, erosionando el Estado de Derecho en lo concerniente al principio de legalidad. de legitimidad al único titular de la soberanía democrática, es decir, al pueblo:

[e]l Estado democrático exige que el pueblo sea soberano; esto es, aquel que en una sociedad tiene la capacidad de dictar normas jurídicas estando en la posesión de un poder supremo, ilimitado, único e indivisible. El pueblo es, en definitiva y con toda su ambigüedad -es en esta ambigüedad donde se sustenta su potencialidad revolucionaria-, el sujeto soberano donde reside el poder constituyente (Martínez, 2012, pp. 8 y 9).

De conformidad con lo anterior, se puede afirmar que no solo en el marco de la Constitución de 1991, sino en función de las dinámicas democráticas de elección popular y de los mecanismos planteados para ello como el referendo, el poder constituyente soberano, esto es, el pueblo colombiano, ${ }^{17}$ tendrá que ser quien presente su posición frente a un eventual acuerdo de paz, a la abolición de la figura de la reelección presidencial, a los límites o incluso la abolición

17 Para entender en concreto cómo el pueblo colombiano es el poder constituyente, se trae a colación el preámbulo y algunos artículos de la Carta Política que ilustran su alcance, así como la existencia de figuras como el referendo, para efectos de los cambios constitucionales: "EL PUEBLO DE COLOMBIA, en ejercicio de su poder soberano, representado por sus delegatarios a la Asamblea Nacional Constituyente, invocando la protección de Dios, y con el fin de fortalecer la unidad de la Nación y asegurar a sus integrantes la vida, la convivencia, el trabajo, la justicia, la igualdad, el conocimiento, la libertad y la paz, dentro de un marco jurídico, democrático y participativo que garantice un orden político, económico y social justo, y comprometido a impulsar la integración de la comunidad latinoamericana, decreta, sanciona y promulga la siguiente CONSTITUCIÓN POLITICA DE COLOMBIA; ARTÍCULO 40. TOdo ciudadano tiene derecho a participar en la conformación, ejercicio y control del poder político. Para hacer efectivo este derecho puede: 1. Elegir y ser elegido. 2. Tomar parte en elecciones, plebiscitos, referendos, consultas populares y otras formas de participación democrática. ARTíCULO 103. Son mecanismos de participación del pueblo en ejercicio de su soberanía: el voto, el plebiscito, el referendo, la consulta popular, el cabildo abierto, la iniciativa legislativa y la revocatoria del mandato. La ley los reglamentará. ARTículo 374. La Constitución Política podrá ser reformada por el Congreso, por una Asamblea Constituyente o por el pueblo mediante referendo". 
de la figura del procurador general de la Nación y frente a la transformación de la acción de tutela. No obstante, es posible que no todas las reformas ocurran desde el ejercicio del poder soberano directo, sino que se presenten a través de normas elaboradas por el Congreso y, en este caso, cabría preguntarse si allí se fractura el proceso constituyente y democrático desde el nuevo constitucionalismo; o si por el contrario, los movimientos que surjan de este, incluso los legislativos, son ejercicios plenos del poder constituyente-constituido ${ }^{18}$ que detentan legitimidad. Al respecto, vale la pena anotar que:

el nuevo constitucionalismo reivindica el carácter revolucionario del constitucionalismo democrático, dotándolo de mecanismos que pueden hacerlo más útil para la emancipación y avance de los pueblos, al concebir la constitución como mandato directo del poder constituyente $y$, en consecuencia, fundamento último de la razón de ser del poder constituido (Viciano y Martínez, 2011, p. 7).

Por otro lado, es importante resaltar el movimiento del poder constituyente, su actividad, su constante proceso de desarrollo, el cual se evidenció en la votación del pasado 15 de junio de 2014 y contrastó claramente con lo ocurrido en la primera vuelta que tuvo lugar el 25 de mayo de 2014. Lo anterior se ilustra, por ejemplo, en un aparte del reporte de Hugo Mario Cárdenas en el diario El País:

18 En este sentido, es preciso aclarar que la movilidad del poder constituyente y su plena autonomía para decidir, o para decidir no decidir, hace que sea posible asumir que el pueblo colombiano podrá gestionar el nuevo cambio constitucional que se derive de la negociación o, incluso, de la no negociación.
Bien por la polarización o bien por el entusiasmo que genera en el país el tema de la paz, las campañas en segunda vuelta lograron que cerca del $8 \%$ de quienes no salieron a votar en mayo pasado decidieran tomar partido en esta segunda vuelta por la Presidencia. La abstención se logró reducir en un 7,6\% y en la jornada del domingo [15 de junio de 2014] hubo 2.578.000 personas más en las urnas que respaldaron mayoritariamente al presidente Juan Manuel Santos (16 de junio de 2014).

Todo lo anterior sirve, además, para evidenciar la diversidad del poder constituyente y su fuerza emancipadora, la cual se expresa no solo en la participación democrática sino en las acciones de los movimientos ciudadanos que lo representan. En esta medida, se pretende dejar insinuada la pluriculturalidad del poder constituyente colombiano en el marco de la consolidación democrática. Al respecto, se retoma lo establecido por Boaventura de Suosa Santos frente a la idea de Estado pluricultural, en su artículo La reinvención del Estado y el Estado plurinacional.

Pero no solo en el caso colombiano sino en el de Ios Estados vecinos, estamos frente a diferentes retos propios del estado plurinacional, y si se logra la paz Colombia deberá enfrentarlos. Entre ellos se destacan: ${ }^{19}$

1. Nuevos lenguajes, diferentes narrativas, distintos imaginarios en la solución de los problemas: el proceso de paz implica reinventarnos no solo en términos de lo imaginado sobre el

\footnotetext{
19 Los retos son tomados de las características que De Sousa (2007, pp. 6 a 8 ) presenta sobre el Estado pluricultural.
} 
posconflicto, sino en la forma de entender a los otros, particularmente a esos otros que se han entendido históricamente como victimarios y no solo haciendo referencia a las guerrillas, sino al Estado mismo y a los paramilitares.

2. Nuevos actores y nuevas prácticas transformadoras, nuevas formas y culturas de organización: se requiere superar el paradigma de la violencia por el de la paz y los nuevos actores que de firmarse esta última tendrían que reincorporarse a la sociedad civil.

3. Neoterritorialidad y cierta desmercantilización: la paz, y particularmente el posconflicto, implicará un nuevo entendimiento sobre la realidad geopolítica nacional, esfuerzos de integración de las regiones y de los municipios más apartados y una reinvención de los espacios que durante tanto tiempo estuvieron en manos de la guerrilla. También se tendría que revaluar el sistema económico, no necesariamente para acabar con el capitalismo pero sí para generar políticas y estrategias más equitativas de redistribución de la riqueza.

4. Una lucha constitucional por la igualdad que es una lucha por el reconocimiento de la diferencia: situación que, en el caso colombiano y en el marco del proceso de paz, exige de todos por lo menos la capacidad de transformar el odio en respeto e inclusión política y social.

5. Finalmente, estaría la idea de incorporar un nuevo modelo de educación popular, que seguramente en medio del proceso de paz implicará para los colombianos reconstruir mitos e histo- rias en función de la memoria de las víctimas y de la reconstitución de la sociedad civil.

\section{BREVES CONCLUSIONES: PROCESO CONSTITUYENTE INCONCLUSO, UN PROCESO EN PERMANENTE CONSTRUCCIÓN, EN PERMANENTE TRANSICIÓN...}

Como autora de esta prematura reflexión que tiene la pretensión de ser retrospectiva, la pregunta que vale la pena hacerse para continuar con el planteamiento del presente texto y para el caso colombiano sería: ¿qué es lo que falta? La respuesta es clara: falta lograr un acuerdo negociado de paz o, de lo contrario, la disolución de los diálogos, que llevaría a continuar con el desgastado statu quo del conflicto armado permanente.

Como se ha venido afirmando, cualquiera de los dos escenarios (la necesidad derivada por el proceso de paz o la ruptura del poder constituido por el fracaso de aquel) podría conllevar la consolidación de un proceso constituyente y su consecuente expresión: un proceso constitucional. Lo anterior, ya sea para afianzar lo señalado en el acuerdo o para buscar la rebelión frente a la historia circular en la que ha vivido el país durante tantas décadas. Estas opciones podrían ser estudiadas desde el neoconstitucionalismo o desde el nuevo constitucionalismo, pero de cada una de estas concepciones teóricas se derivarían consecuencias diversas.

Adicionalmente, los dos escenarios mencionados están acompañados del gran reto que tie- 
ne Colombia en términos de superación de la desigualdad, y que en cualquier momento debería llevar a la acción del poder constituyente en función de lograr acciones y consensos por una sociedad más justa y equitativa.

Por otro lado, continúa la dualidad entre una Constitución que afiance la carta de derechos, las estrategias de igualdad material y la paz como un requerimiento social esencial para la convivencia pacífica de los colombianos, o una Constitución legítima pero que signifique un retroceso en materia de derechos, por un fracaso del proceso y una radicalización conservadora.

\section{Referencias}

Cárdenas López, H. M. (16 de junio de 2014). Así se dividió la votación en los departamentos de Colombia. Obtenido de El País: http:// www.elpais.com.co/elpais/elecciones/noticias/asi-dividio-votacion-departamentoscolombia

Constitución Política de Colombia. (1991). Obtenido de Régimen Legal de Bogotá, D. C.: http://www.alcaldiabogota.gov.co/sisjur/ normas/Norma1.jsp?i=4125

De la Torre, C. (26 de mayo de 2014). Mesa de diálogo con el uribismo. Obtenido de El Espectador: http://www.elespectador.com/ opinion/mesa-de-dialogo-el-uribismo-columna-494693

De Sousa Santos, B. (Septiembre de 2007). La reinvención del Estado y el Estado plurinacio- nal. Observatorio Social de América Latina (22), 25-46. Obtenido de: http://bibliotecavirtual.clacso.org.ar/ar/libros/osal/osal22/ D22SousaSantos.pdf

El Espectador. (19 de marzo de 2014). Cronología del proceso de destitución del alcalde Petro. Obtenido de: http://www.elespectador.com/noticias/bogota/cronologia-del-proceso-de-destitucion-del-alcalde-petro-galeria-481701\#

El Espectador. (26 de mayo de 2014). Mesa de diálogo con el uribismo. Obtenido de: http:// www.elespectador.com/opinion/mesa-dedialogo-el-uribismo-columna-494693

El Espectador. (11 de junio de 2014). Apuesta por la paz. Obtenido de http://www.elespectador.com/opinion/apuesta-paz-columna-497798

El Tiempo. (26 de mayo de 2014). Marta Lucía y Clara fueron las sorpresas. Obtenido de: http://www.eltiempo.com/elecciones-2014/ presidencia/marta-luca-y-clara-fueron-lassorpresas/14036899

El Tiempo. (8 de junio de 2014). Razones de la Corte Suprema para revocar tutela que restituyó a Petro. Obtenido de: http://www.eltiempo.com/politica/justicia/razones-de-la-cortesuprema-para-revocar-tutela-que-restituyo-apetro/14092781

El Tiempo. (9 de junio de 2014). Desmontaré la reforma tributaria que se hizo contra la clase media. Obtenido de: http://www.eltiempo. 
com/politica/partidos-politicos/scar-ivanzuluaga-explica-su-posicion-actual-frente-alproceso-de-paz/14089417

El Tiempo. (s. f.). Colombia busca la paz. Obtenido de: http://www.eltiempo.com/Multimedia/especiales/proceso-de-paz-colombia/

La silla vacía. (3 de septiembre de 2014). Las urnas no definieron el pulso entre Uribe y Santos. Obtenido de: http://lasillavacia.com/ historia/historia-analisis-elecciones-46842

Martínez Dalmau, R. (Julio de 2012). El ejercicio del poder constituyente en el nuevo constitucionalismo. Revista General de Derecho Público Comparado (11).

Presidencia de la República. (s. f.). Proceso de paz. Contenidos más vistos. Obtenido de Urna de Cristal: http://www.urnadecristal. gov.co/busqueda/PROCESO\%20DE\%20PAZ

Quintero Ramírez, O. A. (2002). Sociología e historia del movimiento estudiantil por la Asamblea Constituyente de 1991. Revista Colombiana de Sociología, VII(1), 125-151.

Revista Semana. (15 de junio de 2014). Juan Manuel Santos es reelegido presidente
2014-2018. Obtenido de: http://www.semana.com/Home

Ruiz Navarro, C. (11 de junio de 2014). Apuesta por la paz. Obtenido de El Espectador: http:// www.elespectador.com/opinion/apuestapaz-columna-497798

Sanín Restrepo, R. (7 de marzo de 2014). The 'Lawful' Political Killing of Bogotá's Mayor: Gustavo Petro. Obtenido de Critical Legal Thinking: http://criticallegalthinking. com/2014/03/07/lawful-political-killing-bogotas-mayor/

Uprimny, R. (24 de mayo de 2014). ¿Paz imperfecta o guerra perpetua? Recuperado el 18 de junio de 2014, de El Espectador: http:// www.elespectador.com/opinion/paz-imperfecta-o-guerra-perpetua-columna-494339

Uprimny, R. (7 de junio de 2014). Cinco diferencias decisivas. El Espectador.

Viciano Pastor, R. y Martínez Dalmau, R. (2011). El nuevo constitucionalismo latinoamericano: fundamentos para una construcción doctrinal. Revista General de Derecho Público Comparado, (9), 1-24. 